
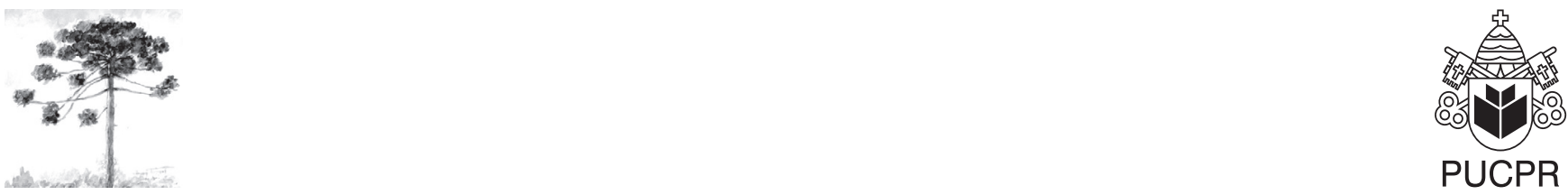

PUCPR

\title{
Avaliação experimental da atividade antibiofilme do digluconato de clorexidina em bases detergentes
}

\author{
Experimental evaluation of the anti-biofilm activity of the \\ chlorhexidine digluconate in detergent bases
}

\author{
Aline Junskowski Kalil ${ }^{[a]}$, Carolina Bernaski Meira ${ }^{[a]}$, Heloísa Titze Thomaz ${ }^{[a]}$, \\ Angela Bonjorno Arantes ${ }^{[b]}$ Edvaldo Antonio Ribeiro Rosa ${ }^{[c]}$
}

[a] Acadêmicas de Farmácia da Pontifícia Universidade Católica do Paraná (PUCPR), Curitiba, PR - Brasil.

[b] Mestre em Ciências Farmacêuticas pela Universidade Federal do Paraná (UFPR), professora assistente de Tecnologia de Cosméticos, Laboratório de Tecnologia de Cosméticos da Pontifícia Universidade Católica do Paraná (PUCPR), Curitiba, PR - Brasil.

[c] Doutor em Biologia e Patologia Buco-Dental pela Universidade Estadual de Campinas (Unicamp), professor titular de Microbiologia (Unidade de Pesquisa com Xenobióticos) da Pontifícia Universidade Católica do Paraná (PUCPR), Curitiba, PR - Brasil. e-mail: edvaldo.rosa@pucpr.br

\section{Resumo}

Um dos maiores problemas a ser resolvido em serviços de saúde é o fato de que muitos micro-organismos patogênicos podem crescer sobre superfícies sob o fenótipo de biofilmes. Células microbianas crescidas sob o fenótipo de biofilmes normalmente se encontram imobilizadas na matriz polimérica extracelular e apresentam foram desenvolvidas três formulações detergentes para uso em ambiente clínico-hospitalar-odontológico, contendo digluconato de clorexidina $2 \%$ em bases catiônica, aniônica e não iônica. Essas formulações foram testadas quanto às suas capacidades de inativação de biofilmes de Staphylococcus aureus ATCC ${ }^{\circledR} 25933^{\circledR}$, Pseudomonas aeruginosa $\mathrm{ATCC}^{\circledR} 27853^{\circledR}$ e Candida albicans SC5314. Foi mensurada a ação detergente das três formulações sobre os biofilmes de $24 \mathrm{~h}$ das três entidades microbianas e foi empregado o ensaio de retenção de cristal violeta $0,5 \%$. De forma surpreendente, na formulação com base aniônica, deforma inversa ao esperado, a clorexidina comprometeu parcialmente a atividade inativante do detergente, talvez por precipitação do tensioativo. Os resultados mostraram que os componentes das formulações detergentes aqui testadas parecem ser mais determinantes na inativação das células microbianas dos biofilmes que a clorexidina.

Palavras-chave: Clorexidina. Biofilmes. Bases detergentes. 


\begin{abstract}
One of the most relevant problems to be solved in heal th services is the fact that pathogenic microbes may grow onto surfaces under a biofilm phenotype. Microbial cells grown as biofilms are entrapped in extracellular polymeric matrixes and show high resistance to environmental aggression, in special, to antimicrobial agents. In this study, it was three developed detergent different formulations containing $2 \%$ chlorhexidine digluconate in cationic, anionic, and non-ionic bases for using in clinical-hospital-dental environments. The detergent action of such formulations was evaluated against $24 \mathrm{~h}$-old biofilms of Staphylococcus aureus ATCC ${ }^{\mathrm{TM}} 25933^{\mathrm{TM}}$, Pseudomonas aeruginosa $A$ TCC $^{\mathrm{TM}} 27853^{\mathrm{TM}}$, and Candida albicans SC5314. The efficiency of such formulations was determined by the $0.5 \%$ crystal violet retention assay. Surprising and against our expectative, results revealed that chlorhexidine partially reduced the detergent activity of anionic base. That may be due to a possible precipitation of surfactants with anionic feature. Obtained results point toward to the possibility that the detergent components of formulations are more determinant for microbial cell inactivation than the chlorhexidine.
\end{abstract}

Keywords: Chlorhexidine. Biofilms. Detergent bases.

\section{Introduçáo}

O digluconato de clorexidina (CHX) é uma bisguanida, com ação antisséptica, utilizada nas áreas médica, veterinária e industrial para a sanitização das mãos, dos alimentos e das superfícies abióticas. A CHX se destaca principalmente pela baixa toxicidade, pelo amplo espectro e por suas propriedades inodoras, incolores e não corrosivas (1).

A opção antisséptica mais efetiva é a forma detergente, por atuar na destruição do biofilme e facilitar o contato do ativo antimicrobiano com as células dos micro-organismos (2). Um detergente, quando adicionado a uma suspensão, provoca a diminuição da tensão superficial, que acarreta em maior capacidade de difusão desta no interior de massas microbianas organizadas, com consequente maior velocidade no desenvolvimento de sua ação antisséptica (3).

Para avaliar o potencial profilático/terapêutico de formulações contendo CHX é imperativo considerar todas as variáveis envolvidas no processo de antissepsia e eleger técnicas que envolvam o crescimento microbiano em sua forma planctônica e de biofilme.

Biofilmes são comunidades de células sésseis caracterizadas pela ligação estável de substratos bióticos ou abióticos. As células se encontram envoltas em matrizes poliméricas extracelulares produzidas pelos micro-organismos (4). Em seus habitats, a maioria dos micro-organismos vive em comunidades com diferentes graus de complexidade, geralmente compondo biofilmes. Uma vezinstalado um biofilme, a resistência dos micro-organismos aos sanificantes se eleva consideravelmente (3).
Neste estudo, foi avaliado o potencial de detergência de três formulações contendo CHX 2\% em bases catiônica, aniônica e não iônica sobre biofilmes de espécies relacionadas a afecções de pele.

\section{Materiais e métodos}

\section{Formulaçóes dos detergentes}

Foram desenvolvidas três diferentes bases detergentes: uma aniônica, uma catiônica e outra não iônica (Tabela 1). As bases sem princípio ativo foram usadas como controles negativos. A CHX foi adicionada até uma concentração de $2 \%$ em cada base.

Algumas adequações farmacotécnicas foram necessárias, como ajuste de viscosidade, correção de $\mathrm{pH}$ e adequações sensoriais subjetivas, como capacidade de formação de espuma.

Quando houve a incorporação da CHX na base aniônica foi observada formação de turvação intensa, o que não se repetiu nas bases I e II. Uma vez preparados os produtos, estes foram submetidos ao acondicionamento que simula condições de disponibilização comercial em temperatura de 45 ${ }^{\circ} \mathrm{C}$, ao abrigo da luz, por 90 dias.

\section{Cepas}

Para a condução deste estudo foram empregadas as cepas Staphylococcus aureus ATCC ${ }^{\circledR} 25933^{\circledR}$, 
Pseudomonas aeruginosa ATCC $^{\circledR} 27853^{\circledR}$ e Candida albicans SC5314.

\section{Formação de biofilmes}

As cepas foram inoculadas em caldo TSB ou caldo Sabouraud e, após $24 \mathrm{~h}$, obtiveram-se suspensões fúngicas $\left(10^{7} \mathrm{UFC} / \mathrm{mL}\right)$ e bacterianas $\left(10^{8} \mathrm{UFC} / \mathrm{mL}\right)$ (5), que foram transferidas $(200 \mu \mathrm{L})$ para placas de poliestireno de 96 poços estéreis. As suspensões permaneceram em contato com o substrato por $4 \mathrm{~h}$ a 37 ${ }^{\circ} \mathrm{C}$ e agitação de $70 \mathrm{rpm}$. Após isso, as células foram drenadas e os substratos foram lavados com água estéril, para a remoção das células não aderidas. Os poços foram preenchidos $(200 \mu \mathrm{L})$ com caldos de cultura (TSB ou caldo Sabouraud). As placas foram incubadas em atmosfera normóxia por intervalos de tempo de $24 \mathrm{~h}$ e temperatura de $37^{\circ} \mathrm{C}$. Terminado o período de incubação os poços foram lavados com água estéril.

\section{Challenge-test com bases detergentes}

Foi realizado o pareamento de tratamentos com as bases sem CHX e seus correspondentes com CHX. Ainda, solução de CHX 1\% em água destilada foi empregada como controle positivo. Como controle duplo negativo foi mantido o biofilme sem qualquer tratamento.

Tabela 1 - Fórmulas dos detergentes antissépticos empregados

\begin{tabular}{|c|c|}
\hline \multicolumn{2}{|c|}{ Base não iônica (Base I) } \\
\hline Lauril poliglucosídeo & $6 \mathrm{~g}$ \\
\hline Decil poliglucosídeo & $12 \mathrm{~g}$ \\
\hline Diestearato de PEG 6000 & $3,5 \mathrm{~g}$ \\
\hline EDTA & $0,1 \mathrm{~g}$ \\
\hline Etanol & $1 \%$ \\
\hline Digluconato de clorexidina & $9,54 \mathrm{~g}(\mathrm{fc}=4,77)$ \\
\hline Água & q.s.p. $100 \mathrm{~g}$ \\
\hline \multicolumn{2}{|c|}{ Base catiônica (Base II) } \\
\hline Lauril poliglucosídeo & $6 \mathrm{~g}$ \\
\hline Decil poliglucosídeo & $12 \mathrm{~g}$ \\
\hline Diestearato de PEG 6000 & $3,5 \mathrm{~g}$ \\
\hline EDTA & $0,1 \mathrm{~g}$ \\
\hline Cloreto de cetiltrimetilamônio ( $50 \%$ em etanol) & $2 \mathrm{~g}$ \\
\hline Digluconato de clorexidina & $9,54 \mathrm{~g}\left(\mathrm{fc}_{\mathrm{c}}=4,77\right)$ \\
\hline Água & q.s.p. $100 \mathrm{~g}$ \\
\hline \multicolumn{2}{|c|}{ Base aniônica (Base III) } \\
\hline Lauril éter sulfato de sódio & $20 \mathrm{~g}$ \\
\hline Cocoamidopropil betaína & $8 \mathrm{~g}$ \\
\hline EDTA & $0,1 \mathrm{~g}$ \\
\hline Cloreto de sódio & q.s.p. \\
\hline Digluconato de clorexidina & $9,54 \mathrm{~g}(\mathrm{fc}=4,77)$ \\
\hline Etanol & $1 \%$ \\
\hline Água & q.s.p. $100 \mathrm{~g}$ \\
\hline
\end{tabular}

Fonte: Dados da pesquisa. 
As formulações foram previamente diluídas 1:1 em água destilada estéril (para mimetizar enxague prévio) e alíquotas de $200 \mu \mathrm{L}$ foram aplicadas com micropipeta 12 canais. Decorridos 30 segundos, os conteúdos dos poços foram aspirados e os poços imediatamente receberam $200 \mu \mathrm{L}$ de complexo neutralizante composto de Tween ${ }^{\circledR} 802 \%$; lecitina de soja $1,17 \%$; Triton ${ }^{\circledR}$ X-100 0,1\% e tiossulfato de sódio $0,5 \%$ (6). O neutralizante foi mantido por 5 minutos, até ser aspirado. Os poços foram lavados com água estéril, duas vezes. Os conteúdos celulares dos biofilmes foram estimados pelo ensaio de retenção de cristal violeta.

\section{Quantificação de biofilme pelo ensaio de retenção de cristal violeta}

Os biofilmes foram primeiramente lavados duas vezes com $200 \mu \mathrm{L}$ de água estéril. Para a fixação dos biofilmes, $100 \mu \mathrm{L}$ de metanol 99\% foram adicionados aos poços das placas de microtitulação por 15 minutos. O metanol foi removido e as placas foram secas ao ar. Alíquotas de $200 \mu \mathrm{L}$ de solução de cristal violeta (CV) 0,5\% foram adicionadas aos poços. Após 20 minutos, o excesso de CV foi removido lavando-se a placa com água corrente.

Finalmente, o CV impregnado foi liberado pela adição de $250 \mu \mathrm{L}$ de ácido acético $33 \%$. A densidade óptica a $540 \mathrm{~nm}\left(\mathrm{OD}_{540 \mathrm{~nm}}\right)$ foi determinada em leitora de placas TP-Reader ${ }^{\circledR}$ (ThermoPlate, Inc.). Os valores de absorbância dos blankes foram subtraídos dos valores obtidos nos tratamentos para eliminar resultados espúrios decorrentes de interferência de fundo (5).

\section{Estatística}

Os testes anteriormente descritos foram conduzidos em quadruplicatas em três diferentes situações, perfazendo doze repetições. Os dados numéricos obtidos foram tabulados em planilhas eletrônicas Microsoft Excel ${ }^{\circledR}$ (Microsoft Co.). Para se testar a hipótese nula de que qualquer diferença encontrada nos tratamentos se devia meramente ao acaso, esses dados foram testados: quanto à sua normalidade de distribuição - pelo teste de Kolmogorov-Smirnov; e dehomogeneidade de variância-pelo teste deLevene.
Como as distribuições foram consideradas normais e houve homogeneidade de variância, os resultados foram submetidos às comparações múltiplas pelo teste de Tukey HSD. As diferenças entre as médias foram consideradas significativas quando o valor $p$ era igual ou inferior a 0,05 .

\section{Resultados e discussáo}

O Gráfico 1 mostra o desempenho dos detergentes em biofilmes de $S$. aureus ATCC ${ }^{\circledR} 25933^{\circledR}$, sendo os resultados da base não iônica sem $\mathrm{CHX}$ e da base catiônica contendo CHX estatisticamente iguais ao do controle negativo ( $p>0,05)$. Tal fato pode ser interpretado como que essas formulações inativaram quantidades de biofilme iguais àquelas que o $\mathrm{CHX}$ 1\% inativou. A formulação não-iônica acrescida de CHX apresentou menor eficiência na remoção do biofilme aderido às superfícies acrílicas da placa. Tanto a formulação aniônica com CHX quanto sua correspondente sem $\mathrm{CHX}$ forneceram resultados mais efetivos que o controle positivo na remoção do biofilme. Isso ganha relevância, pois mostra que a ação das bases detergentes na desestabilização da estrutura do biofilme estafilocócico é maior que aquela propiciada pela mera solução aquosa de clorexidina $1 \%$ e que sabões permanecem sendo as formas farmacêuticas mais indicadas para a inativação de biofilmes. Some-se a isso o fato de que os tratamentos foram conduzidos unicamente por contato por 30 segundos e sem qualquer ação mecânica posterior.

Em se excetuando a base não iônica acrescida de CHX, os demais tratamentos foram mais eficazes que a solução aquosa de $\mathrm{CHX} 1 \%$ na redução de biofilme de P. aeruginosa ATCC ${ }^{\circledR} 27853^{\circledR}(\mathrm{p}<0,05)$ (Gráfico 2). Embora não haja discrepâncias ( $\mathrm{p}>0,05)$ entre as bases aniônica e catiônica, ambas com ou sem CHX, é perceptível uma redução no biofilme, da ordem de 3,04 vezes, promovida pelo detergente não iônico sem CHX, em relação ao tratamento com CHX 1\%. Assim como anteriormente discutido, os componentes das bases detergentes também são determinantes na desestruturação dos biofilmes de $P$. aeruginosa ATCC ${ }^{\circledR} 27853^{\circledR}$, talvez em razão de suas propriedades surfactantes. Estudos posteriores envolvendo os componentes das formulações de forma isolada podem revelar se essa hipótese é verdadeira ou não. 


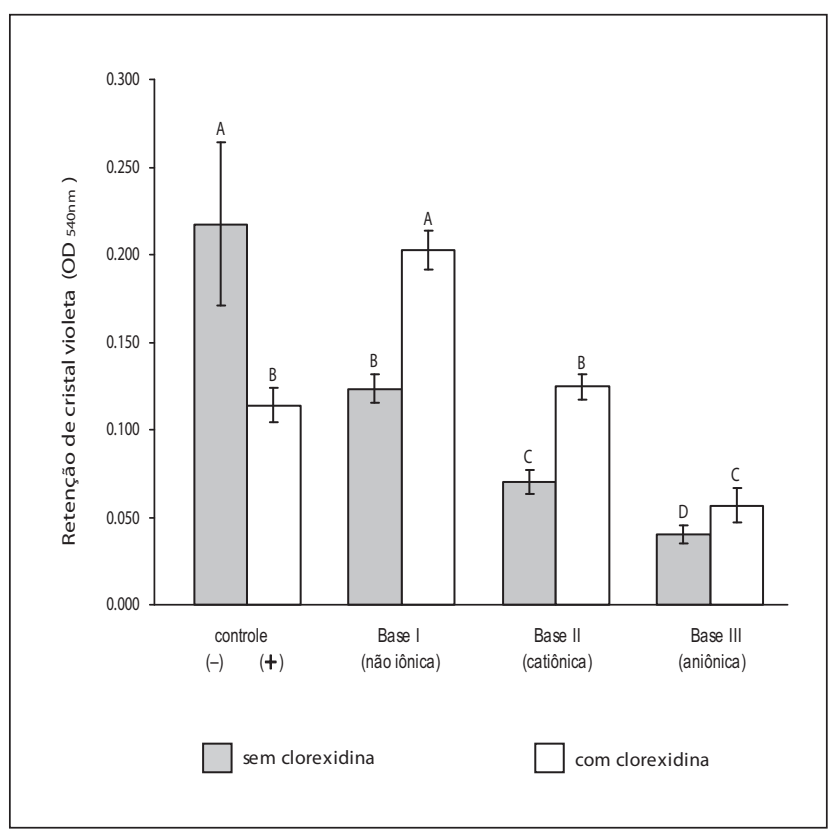

Gráfico 1 - Redução de biofilme de $S$. aureus ATCC $^{\circledR} 25933^{\text {TM }}$ crescida em biofilmes de $24 \mathrm{~h}$

Nota: letras diferentes denotam diferença estatística (teste de Tukey HSD; $\mathrm{p}<0,05)$.

Fonte: Dados da pesquisa.

A C. albicans SC5314é um micro-organismo que sabidamente produz quantidades consideráveis de biofilme, mesmo em condições desfavoráveis (7). Em comparação ao tratamento com solução aquosa de CHX 1\%, somente os tratamentos com base catiônica sem CHX e base aniônica com CHX se mostraram mais eficientes ( $p<0,05)$ (Gráfico 3). Aliás, a exposição à base não iônica com $\mathrm{CHX}$ comprometeu a eficiência a ponto de se igualar quantitativamente ao controle duplo negativo, que não sofreu qualquer desafio com detergentes ou antimicrobianos $(p>0,05)$.

Qualquer suposição de que o digluconato de clorexidina empregado se apresentou degradado ou que houvesse perdido sua propriedade antimicrobiana foi descaracterizada, uma vez que a solução aquosa $1 \%$ foi preparada com a mesma partida da disguanida e que os ensaios-controle comparativos entre biofilmes que receberam a solução e que não receberam qualquer tratamento foram conclusivos ( $\mathrm{p}<0,001)$.

Ao menos em parte, a redução na atividade desagregadora dos biofilmes analisados promovida pela CHX pode ser decorrente da incompatibilidade iônica entre o antisséptico e os componentes da formulação. A CHX apresenta problemas de compatibilidade com surfactantes aniônicos em razão da sua natureza dicatiônica, que a torna extremamente interativa com ânions. Isso é determinante para os quesitos de eficiência, segurança de uso, efeitos colaterais e dificuldade nas formulações (8). Sendo assim, o efeito antimicrobiano da CHX se apresenta reduzido em suspensões contendo ânions. O laurilssulfato de sódio (SDS) e a CHX são incompatíveis quando utilizados clinicamente de forma conjunta e nas concentrações para propósitos clínicos, podendo se comportar como antagonistas (9). Com base nesses pressupostos, para fins odontológicos, foi recomendado que fosse observado um intervalo mínimo de 30 minutos entre a escovação com o dentifrício contendo SDS e o bochecho com solução de CHX $0,2 \%$ para que esta pudesse agir de forma efetiva.

É necessário esclarecer que a metodologia empregada permitiu a verificação da ação das bases detergentes sobre a integridade do biofilme, sem, contudo, verificar a viabilidade dos micro-organismos após os desafios. Estudos que envolvem contagens celulares revelaram se a CHX adicionada às formulações exerce algum efeito microbicida, como amplamente aceito para soluções aquosas (6).

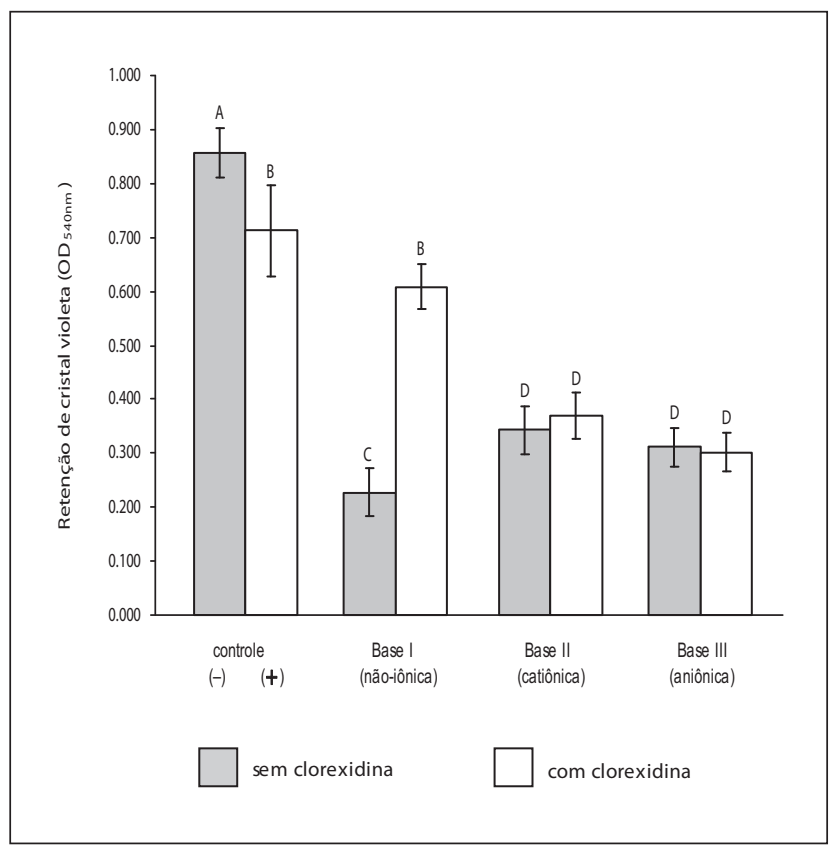

Gráfico 2 - Redução de biofilme de P. aeruginosa ATCC ${ }^{\circledR}$ $27853^{\mathrm{TM}}$ crescida em biofilmes de $24 \mathrm{~h}$

Nota: letras diferentes denotam diferença estatística (teste de Tukey HSD; $\mathrm{p}<0,05)$.

Fonte: Dados da pesquisa. 


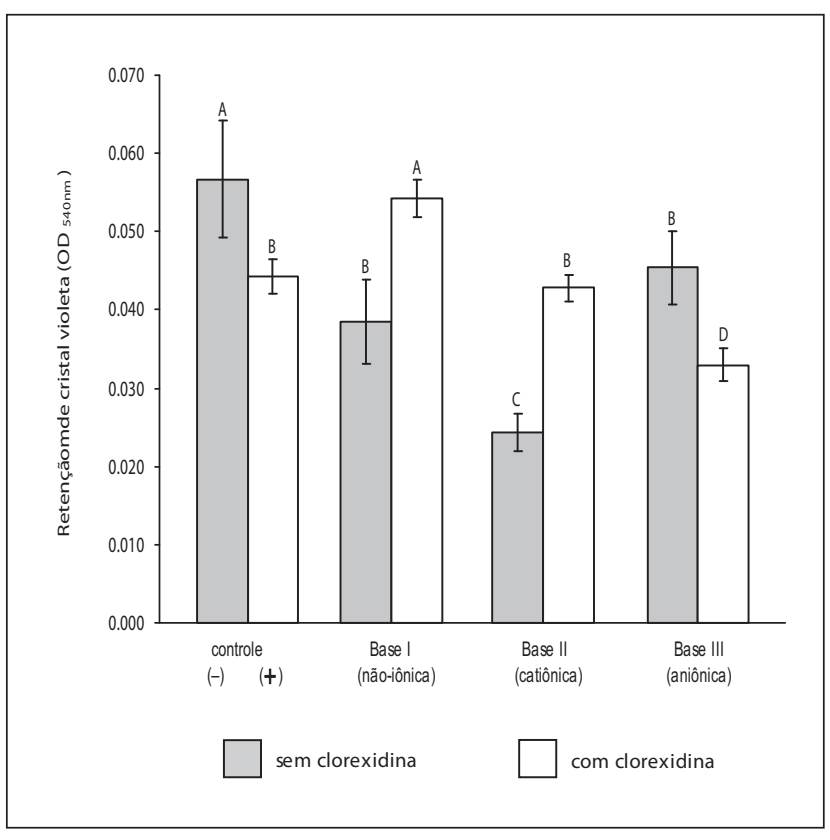

Gráfico 3 - Redução de biofilme de C. albicans SC5314 crescida em biofilmes de $24 \mathrm{~h}$

Nota: letras diferentes denotam diferença estatística (teste de Tukey HSD; $\mathrm{p}<0,05)$.

Fonte: Dados da pesquisa.

\section{Referências}

1. McDonell G, Russel AD. Antiseptics and disinfectants: activity, action, and resistance. Clin Microbiol Rev. 1999;12(1):147-79.

2. Caixeta DS. Sanificantes químicos no controle de biofilmes formados por duas espécies de Pseudomonas em superfície de aço inoxidável [dissertação]. Lavras: Universidade Federal de Lavras; 2008.
3. Seabra EJG, Lima IPC, Barbosa SV, Lima KC. Atividade antimicrobiana "in vitro" de compostos a base de hidróxido de cálcio e tergentol ou em diferentes concentrações sobre bactérias orais. Acta Cirur Brasil. 2005;20(Supl 1):27-33.

4. Costerton JW, Montanaro L, Arciola CR. Biofilm in implant infections: its production and regulation. Int J Artif Organs. 2005;28(11):1062-8.

5. Peeters E, Nelis HJ, Coenye T. Comparison of multiple methods for quantification of microbial biofilms grown in microtiter plates. J Microbiol Methods. 2008;72(2):157-65.

6. Adams D, Quayum M, Wothington T, Lambert P, Elliott T. Evaluation of a 2\% chorhexidine gluconate in 70\% isopropyl alcohol skin disinfectant. J Hosp Infect. 2005;61(4):287-90.

7. Thein ZM, Samaranayake YH, Samaranayake LP. In vitro biofilm formation of Candida albicans and non-albicans Candida species under dynamic and anaerobic conditions. Arch Oral Biol. 2007;52(8):761-7.

8. Lindhe J. Tratado de periodontia clínica e implantologia oral. 3 a ed. Rio de Janeiro: Guanabara Koogan; 1997.

9. Barkvoll P, Rolla G, Svendsen AK. Interaction between chlorexidine gluconate and sodium lauryl sulfate in vivo. J Clin Periodontol. 1989;16(9):593-5.

Recebido: 02/06/2009 Received: 06/02/2009

Aprovado: 03/09/2009 Approved: 09/03/2009 